\title{
Determination of oceanic ozone deposition by ship-borne eddy covariance flux measurements
}

\author{
L. Bariteau ${ }^{1}$, D. Helmig ${ }^{2}$, C. W. Fairall ${ }^{3}$, J. E. Hare ${ }^{1}$, J. Hueber ${ }^{2}$, and E. K. Lang ${ }^{2}$ \\ ${ }^{1}$ Cooperative Institute for Research in Environmental Sciences (CIRES), University of Colorado, Boulder, Colorado, USA \\ ${ }^{2}$ Institute of Alpine and Arctic Research (INSTAAR), University of Colorado, Boulder, Colorado, USA \\ ${ }^{3}$ National Oceanic and Atmospheric Administration (NOAA), Earth System Research Laboratory (ESRL), Boulder, \\ Colorado, USA
}

Received: 9 June 2009 - Published in Atmos. Meas. Tech. Discuss.: 19 August 2009

Revised: 4 February 2010 - Accepted: 3 March 2010 - Published: 12 April 2010

\begin{abstract}
A fast response ozone analyzer based on the ozone-nitric oxide chemiluminescence method was integrated into the NOAA-ESRL flux system to achieve the first ship-borne, direct ozone flux measurements over the open ocean. Air was collected from an inlet at $18 \mathrm{~m}$ height over the ocean surface mounted to the bow-jackstaff and via a $30 \mathrm{~m}$-long sampling line to the ozone instrument on the ship deck. A "puff" system was used for accurate and regular determination of the sample transport time (lag) between the inlet and the chemical analyzer. A Nafion-membrane dryer facilitated removal of fast water vapor fluctuations, which eliminated the need for quenching and density correction of the ozone signal. The sampling-analyzer system was found to have a $\sim 0.25-0.40 \mathrm{~s}$ response time at a sensitivity of $\sim 2800$ counts $^{-1}$ per ppbv of ozone. Quality control and data filtering procedures for eliminating data that did not meet measurement requirements were critically evaluated. The new ozone flux system was deployed aboard the NOAA Ship Ronald H. Brown, and evaluated using results obtained during several research cruises off the coasts of the North and South America continents, yielding ozone deposition velocities (mean \pm standard error) ranging from $0.009 \pm 0.001 \mathrm{~cm} \mathrm{~s}^{-1}$ to $0.24 \pm 0.020 \mathrm{~cm} \mathrm{~s}^{-1}$.
\end{abstract}

\section{Introduction}

A significant term in the global tropospheric ozone budget is the uptake by oceans, with an estimated $200-300 \mathrm{Tg} \mathrm{yr}^{-1}$ of ozone being deposited to the ocean surface (Ganzeveld et al., 2009). Despite this important ozone sink term, direct observations of open oceanic ozone flux are scarce. Previous data have been obtained from laboratory experiments, coastal tower observations, or by airborne flux measurements (see summary in Ganzeveld et al., 2009). Uncertainties in the ocean exchange rate can have significant consequences for global budgets; therefore open ocean observations with concurrent description of the ocean's biological, chemical and physical properties are important for better definition of the dependencies of ozone fluxes. In the literature, past experiments show a wide range of ozone deposition rates, with reported deposition velocities $\left(v_{d}\right)$ spanning from $\sim 0.01$ to $0.15 \mathrm{~cm} \mathrm{~s}^{-1}$ for ocean water, and $0.01-0.10 \mathrm{~cm} \mathrm{~s}^{-1}$ for fresh water (Ganzeveld et al., 2009). Current global climate models typically use a constant ozone deposition velocity value for ocean surfaces on the order of $\sim 0.013$ to $0.05 \mathrm{~cm} \mathrm{~s}^{-1}$ (Ganzeveld and Lelieveld, 1995; Shon et al., 2002).

Eddy-Covariance (EC) is the preferred technique for measuring surface gas fluxes since it allows measurements above the surface at high temporal resolution without disturbing the environment under consideration. In the atmospheric surface layer EC requires measurements at a sufficiently fast rate $(<1 \mathrm{~s})$ to effectively capture the majority of turbulence frequencies contributing to the flux. Only a few ozone ocean flux studies have relied on the EC measurement approach, and these were obtained from fixed tower platforms (Gallagher et al., 2001; Whitehead et al., 2009) or by aircraft turbulent flux measurements (Lenschow et al., 1981, 1982; Kawa and Pearson, 1989). EC measurements from ships have been accomplished for $\mathrm{CO}_{2}$ (McGillis et al., 2001, 2004) and DMS (Blomquist et al., 2006, 2010; Huebert et al., 2004), but to the best of our knowledge, ship borne EC ozone flux measurements have not yet been reported.

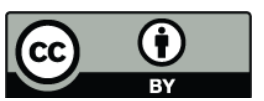

Correspondence to: D. Helmig

(detlev.helmig@colorado.edu)

Published by Copernicus Publications on behalf of the European Geosciences Union. 
The construction of a highly sensitive, fast-response chemiluminescence instrument has enabled us to realize such measurements aboard the National Oceanic and Atmospheric Administration (NOAA) Research Vessel (R/V) Ronald $H$. Brown. The newly developed sensor was integrated into the Earth System Research Laboratory (ESRL, formerly the Environmental Technology Laboratory, ETL) sea-going flux and meteorology measurement system, and it has been deployed during several ocean research cruises. In this paper, we use first measurements obtained for both open-ocean and coastal sites for an evaluation of this new ozone flux system. In Sect. 2, the ozone instrument used for the experiments is fully described. Section 3 presents auxiliary information on the deployment conditions. A discussion of data analysis issues is then provided in Sect. 4, with the examination of the results shown in Sect. 5. Finally, conclusions are given in Sect. 6.

\section{Ozone instrument}

Ozone fluxes over water are generally lower than over vegetated land surfaces, and measuring these low fluxes requires highly sensitive instrumentation. The precision of the gas measurement needs to be sufficient to resolve the relatively small changes in atmospheric mixing ratio, and measurements need to be conducted at high temporal resolution. Typically, EC measurements are performed at frequencies of $\sim 10 \mathrm{~Hz}$. However, depending on the surface roughness, measurement height, and magnitude of the flux to be measured, this requirement can be relaxed to somewhat lower frequency. Micrometeorological approaches for estimating the required instrument sensitivity for EC flux measurements have been presented in the literature (Lenschow and Kristensen, 1985; Businger and Delany, 1990; Delany, 1993). Lenschow and Kristensen (1985) showed that the minimum count rate required to measure the flux without a significant contribution of the counting noise to the flux error can be estimated from:

$$
\langle X\rangle \xi \geq \frac{0.06 u_{*}^{2} / v_{d}^{2}}{\Gamma},
$$

where $\langle X\rangle$ is the mean gas concentration (the brackets denote the time average), $\xi$ is the instrument sensitivity (counts per unit time per unit concentration), $\Gamma$ is the integral time scale (s), $u_{*}$ is the friction velocity $\left(\mathrm{m} \mathrm{s}^{-1}\right)$, and $v_{d}$ is the scalar surface deposition velocity $\left(\mathrm{m} \mathrm{s}^{-1}\right)$ defined at the measurement height $z(\mathrm{~m})$ above the surface $\left(v_{d}(z)=-\right.$ Flux $\left./ X\right)$. The integral time scale for vertical velocity fluctuations, $\Gamma$, can be expressed by:

$\Gamma=a z / U$,

where $a$ is a constant that can vary from 0.3 for neutral conditions (Lenschow and Kristensen, 1985) to 12 for convective conditions (Fairall et al., 2000), and $U$ is the mean wind velocity $\left(\mathrm{m} \mathrm{s}^{-1}\right)$. For an $18 \mathrm{~m}$ measurement height and at $U=6 \mathrm{~m} \mathrm{~s}^{-1}, \Gamma=0.9 \mathrm{~s}$ for neutral conditions. Using this integral time scale value in Eq. 1 with a target deposition velocity $v_{d}$ of $0.05 \mathrm{~cm} \mathrm{~s}^{-1}$ to be resolved, and with values of $20 \mathrm{ppbv}$ for the ambient ozone volume mixing ratio, and at $0.2 \mathrm{~m} \mathrm{~s}^{-1}$ for $u_{*}$ (at $U=6 \mathrm{~m} \mathrm{~s}^{-1}$; McGillis et al., 2001), it follows that the total count rate required is greater than or equal to $\sim 11000$ counts $\mathrm{s}^{-1}$, which corresponds to a sensitivity of $\sim 600$ counts $\mathrm{s}^{-1} \mathrm{ppbv}^{-1}$ for this neutral stability example. This estimate can be considered as rather conservative (worst case scenario). In EC, one hour means are typically used to average over the whole turbulence frequency distribution and natural atmospheric variability. Longer averaging times and compositing multiple one-hour averages will therefore further reduce the uncertainty in this measurement.

Ozone detection based on the ozone + NO chemiluminescence reaction has been proven to be a highly sensitive technique for EC ozone flux measurements (Stedman et al., 1972; Ridley and Grahek, 1990). The fast response ozone chemiluminescence instrument (hereafter FRCI) operates on the basis of reaction of $\mathrm{O}_{3}$ with $\mathrm{NO}$ forming excited $\mathrm{NO}_{2}^{*}$, with $\mathrm{NO}_{2}^{*}$ returning to the ground state emitting a photon at $600 \mathrm{~nm}<\lambda<2800 \mathrm{~nm}$, with the emitted photons being detected with a photomultiplier tube (PMT) detector. A schematic of the instrument is presented on Fig. 1. Sample air was pulled through a $30 \mathrm{~m}$ sampling line (Teflon-PFA, perfluoroalkoxy copolymer) with inner and outer diameters of 0.64 and $0.95 \mathrm{~cm}$, respectively. The sampling line inlet consisted of a PFA in-line filter holder (Savillex Corp., Minnetonka, MN) that was cut open on the inlet side. The inlet filter holder accommodated a Teflon membrane filter $(5 \mu \mathrm{m}$, Millipore, Billerica, MA, USA). Later (see more discussion below), the filter was moved towards the end of the sampling line for easier filter replacement. To avoid possible sampling losses of ozone, all Teflon tubing and filters were conditioned prior to field use by purging with air containing $\sim 300 \mathrm{ppbv}$ of ozone for approximately $15 \mathrm{~h}$ at a flow rate of $41 \mathrm{~min}^{-1}$. A pressure sensor (Kavlico Corporation, Moorpark, CA, USA) was used to monitor the pressure drop within the sampling line. From the sampling line, two $0.64 \mathrm{~cm}$ o.d. Teflon-PFA tubes extended to an UV-absorption $\mathrm{O}_{3}$ monitor (Monitor Lab 8810, Measurement Controls Corporation, Englewood, CO, USA) and to the FRCI, respectively. The UV ozone monitor was calibrated against a TEI 49C ozone analyzer (Thermo Scientific, Aurora, CO, USA), which was referenced against an EPA standard. Stainless steel tubing was used for the NO tubing, and black Teflon tubing was used to connect the sampling line to the $44 \mathrm{~cm}^{3}$-volume, conical, gold-plated reaction chamber (RC) (Ridley et al., 1992). Flow rates were controlled by mass flow controllers (MFC, Tylan-2900, Coastal, Plano, TX, USA), and the RC temperature was maintained at $28^{\circ} \mathrm{C}$ with a temperature controller and heater. The RC pressure was monitored and controlled at 18 Torr by a pressure controller (UPC 1300, Coastal Instrument Inc.). The emitted photons were detected by a PMT 


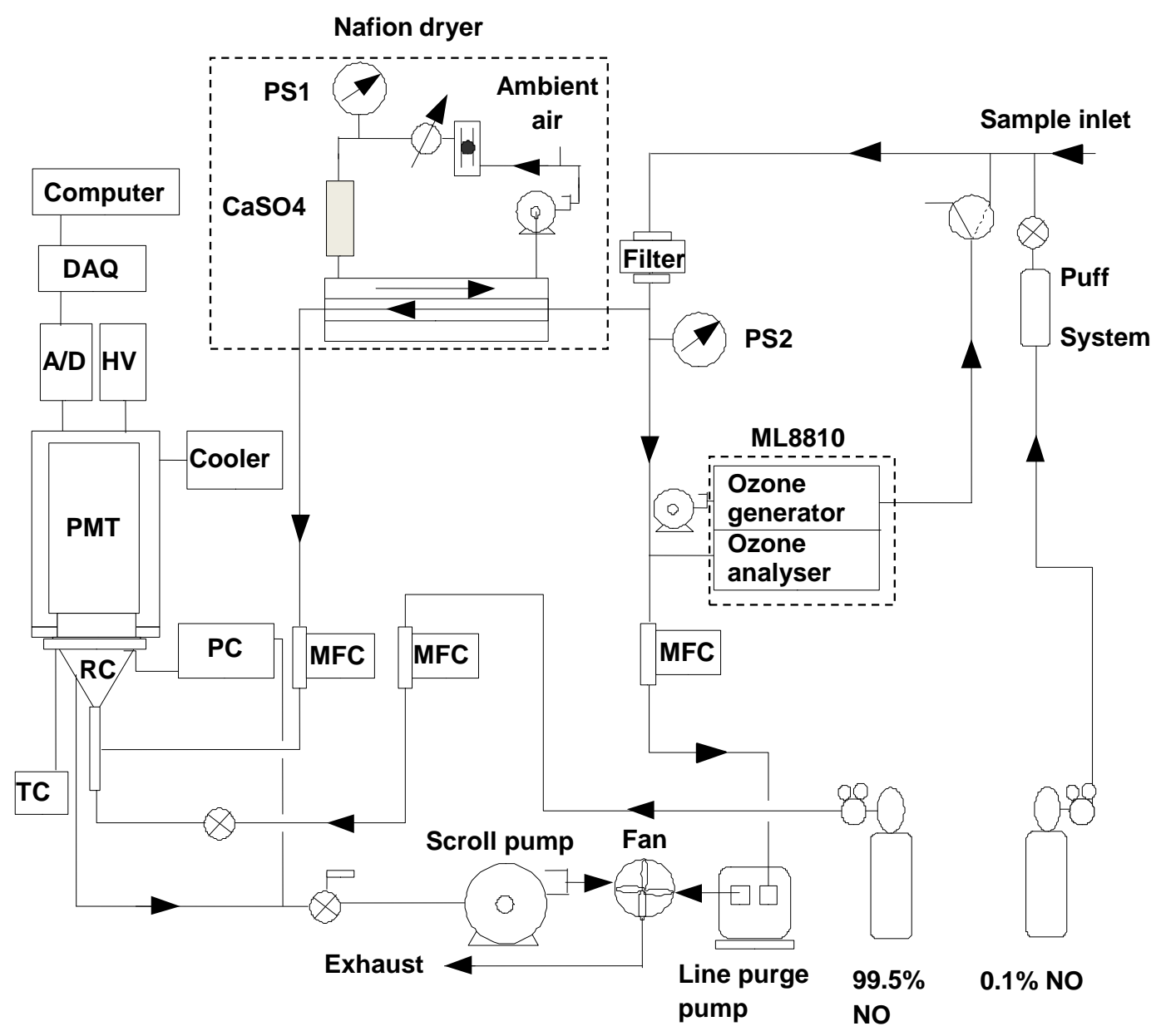

Fig. 1. Plumbing diagram of the ozone flux instrument. Labels are as follows: A/D amplifier/discriminator, DAQ data acquisition, HV high voltage, MFC mass flow controller, PC pressure controller, PMT photomultiplier tube, PS pressure sensor, RC reaction chamber, TC thermocouple. The Nafion drying circuit, including the $\mathrm{CaSO}_{4}$ - filled drying cartridge, was added in 2007.

(Hamamatsu Photonics K. K., Shizuoka, Japan), with a cutoff filter (RG-610, Newport Industrial Glass, Stanton, CA) eliminating radiation with $\lambda<600 \mathrm{~nm}$. Cooling of the PMT was necessary to lower the dark current. The PMT was initially cooled with an immersion cooler to $\sim-20^{\circ} \mathrm{C}$. This cooler was later replaced with an integrated PMT housing Peltier cooler (Hamamatsu, Model C10372, Japan), which lowered the PMT operational temperature to $\sim-35^{\circ} \mathrm{C}$. Calibrations of the FRCI were carried out using ozone standards generated from ambient air, passing through an ozonizer in the Monitor Lab UV instrument, and were performed every 5 days on average. Calibrations were done by standard addition, directing ozone-enriched air to a tee $\sim 50 \mathrm{~cm}$ downstream from the inlet through $0.32 \mathrm{~cm}$ o.d. Teflon tubing. All electrical devices were computer-controlled with a sixteen channel data acquisition system (National Instrument, Austin, TX, USA).

Tests to optimize the FRCI performance were first carried out in the laboratory, and then outside at the Table Mountain research facility north of Boulder, CO. During these tests the sensitivity of the ozone signal as a function of reaction chamber temperature and pressure, the PMT temperature, and the NO and sample flow rates were investigated. The goal was to optimize the instrument sensitivity (number of counts per second per ppbv and the signal-to-noise ratio) and response time, in consideration of the requirements for the measurements on the ship. Parameters that were found to yield best results and which were subsequently used during the cruise deployments were: reaction chamber temperature of $28-29^{\circ} \mathrm{C}$, total sampling line purge flow rate of $11-171 \mathrm{~min}^{-1}$ (dependant on sampling line length and pump used in each particular experiment), sample flow of $1.25-1.501 \mathrm{~min}^{-1}$, PMT temperature of $-20^{\circ} \mathrm{C}$ (later lowered to $-35^{\circ} \mathrm{C}$ ), reaction chamber pressure of 18 Torr, PMT high voltage of $1500 \mathrm{~V}$, and NO flow of $3 \mathrm{ml} \mathrm{min}^{-1}$. With the sampling line purge flow rate of $11-171 \mathrm{~min}^{-1}$ (resulting Reynolds Number of 2460-3800), the air flow is maintained outside of the laminar regime, which is important for obtaining a more uniform velocity profile inside the tubing and for reducing the loss of fast turbulence 
signal. At the $3 \mathrm{ml} \mathrm{min}^{-1} \mathrm{NO}$ flow $\sim 80 \%$ of maximum sensitivity was achieved; this setting was chosen as a compromise between achieving high sensitivity while minimizing the necessary NO usage. Graphical results from these experiments, illustrating the instrument response as a function of the sample flow rate, NO flow rate, the RC pressure, and the RC temperature are shown in the Supplemental Materials Section Figs. S1-S3 (http://www.atmos-meas-tech.net/ 3/441/2010/amt-3-441-2010-supplement.pdf). Under these flow and pressure conditions the theoretical sample residence time in the reaction chamber is $\sim 0.04 \mathrm{~s}(25 \mathrm{~Hz})$, which is sufficient for achieving the $10 \mathrm{~Hz}$ target measurement frequency for EC. With this configuration the instrument had a dark current (at zero ozone) of $3000-4000{\text { counts } s^{-1}}^{-}$The instrument sensitivity was 2800 counts $\mathrm{s}^{-1} \mathrm{ppbv}^{-1}$, resulting in a $10 \mathrm{~Hz}$ signal/noise ratio of $\sim 73$ at $20 \mathrm{ppbv}$ of ozone.

Replacement of the immersion cooler in 2008 with the Peltier PMT housing cooler further reduced the PMT temperature to $\sim-35^{\circ} \mathrm{C}$, which resulted in a reduction of the dark count to $\sim 400$ counts $\mathrm{s}^{-1}$, and an improvement of the $10 \mathrm{~Hz} S / N$ ratio to $\sim 75$ at $20 \mathrm{ppbv}$ of ozone. Please note that another factor influencing the noise is counting statistics, with the counting noise $(N)$ contribution being $N=\sqrt{N_{t}}$, where $N_{t}$ is the total number of counts in the time interval $\Delta t$. Consequently, at lower ozone levels the dark current will have a determining influence in the $S / N$ ratio, whereas at higher ozone concentration, as the total number of counts increase, counting statistics will have the higher influence on the noise. Consequently, the $S / N$ ratio will increase with increasing ozone mixing ratio, which will result in more favorable measurement conditions at higher ozone concentrations. A more detailed discussion of the $S / N$ ratio calculation and comparison between theoretical and experimentally determined $S / N$ results are provided in the Supplement Materials Section. We have also operated this instrument with a $2 \% \mathrm{NO}$ mixture (in $\mathrm{N}_{2}$ ) at a reactant gas flow rate of $\sim 150 \mathrm{ml} \mathrm{min}^{-1}$, and a reduced sample air introduction rate of $\sim 1.351 \mathrm{~min}^{-1}$. The sensitivity achieved in this configuration was $\sim 2200$ counts $\mathrm{s}^{-1} \mathrm{ppbv}^{-1}$. At constant operational conditions the FRCI has been found to exhibit a stable sensitivity over weeks of operation in the field. Results from regular calibrations over the 25 days of operation during the GOMECC-2007 cruise showed less than a $4 \%$ drift (Fig. S4, http://www.atmos-meas-tech.net/3/441/2010/ amt-3-441-2010-supplement.pdf).

The ozone instrument was integrated into the NOAAESRL ship-based turbulent flux measurement system detailed in Fairall et al. (1997, 2003). The following outlines specific aspects of this measurement system that are relevant to computing ozone fluxes. The centerpiece of the flux system is a Gill RS-3A sonic anemometer, which measures the fine-scale three components of the wind vector and the sonic temperature. A Systron-Donner Motionpak forms the mounting base of the sonic anemometer and provides the high-frequency platform motions by measuring the three orthogonal angular rates and accelerations. Lower-frequency ship motions are obtained from a Global Positioning System (GPS), a gyrocompass, and the ship's Doppler speed log. The corrected wind velocity components are obtained by applying rotations to account for pitch, roll, and yaw, along with corrections for the ship's velocity vector. More detailed description on correcting the measured velocity components into fixed-earth coordinates is given by Edson et al. (1998). The FRCI does not appear to respond to the ship's motion as there is no detectable spike at the frequency of the ship's rolling frequency $(\sim 0.25 \mathrm{~Hz})$ in the raw ozone spectrum or flux cospectrum. A high-speed open path infrared hygrometer (LI-COR-7500, LI-COR Inc., Lincoln, NE) was mounted $\sim 1 \mathrm{~m}$ to the side to the ozone inlet for fast-response measurements of water vapor and carbon dioxide concentrations. The sonic temperature was corrected for velocity crosstalk and the humidity contribution, as discussed in Fairall et al. (1997). Water vapor corrections were applied to the ozone concentrations and will be discussed further down in the paper.

The flux system was deployed on a jackstaff located directly above the bow of the ship at $18 \mathrm{~m}$ above the sea surface. As seen in Fig. 2, the sampling line ran from the mast to the instrument box on the third deck of the ship.

\section{Cruise description}

The instrument has been deployed on board the NOAA ship Ronald H. Brown during several cruises. Results reported here are from the Texas Air Quality Study (TexAQS) and Gulf of Mexico Atmospheric Composition and Climate Study (GoMACCS) 2006 research cruise (July to September of 2006), which took place in the northwestern Gulf of Mexico and focused on coastal atmospheric dynamic and chemical processes that affect air quality. In October-November of 2006, a climate processes study was performed on the same ship in the marine stratocumulus region off Northern Chile (STRATUS-2006). Included on this cruise were systems measuring cloud microphysics and near-surface aerosols to study effects on the reflectivity and precipitation of marine stratus clouds. In July-August 2007, the Gulf of Mexico and East Coast Carbon (GOMECC) cruise was conducted along the coasts of the Gulf of Mexico and the Atlantic to study carbon cycle processes in the transition from the open ocean to the coastal zone. From February to April 2008, the Southern Ocean Gas Exchange experiment (SO-GasEx) took place in the Atlantic region of the Southern Ocean. The main purpose of this campaign was to investigate the various processes controlling air-sea gas exchange under high wind conditions. The tracks of all four cruises are shown in Fig. 3. 

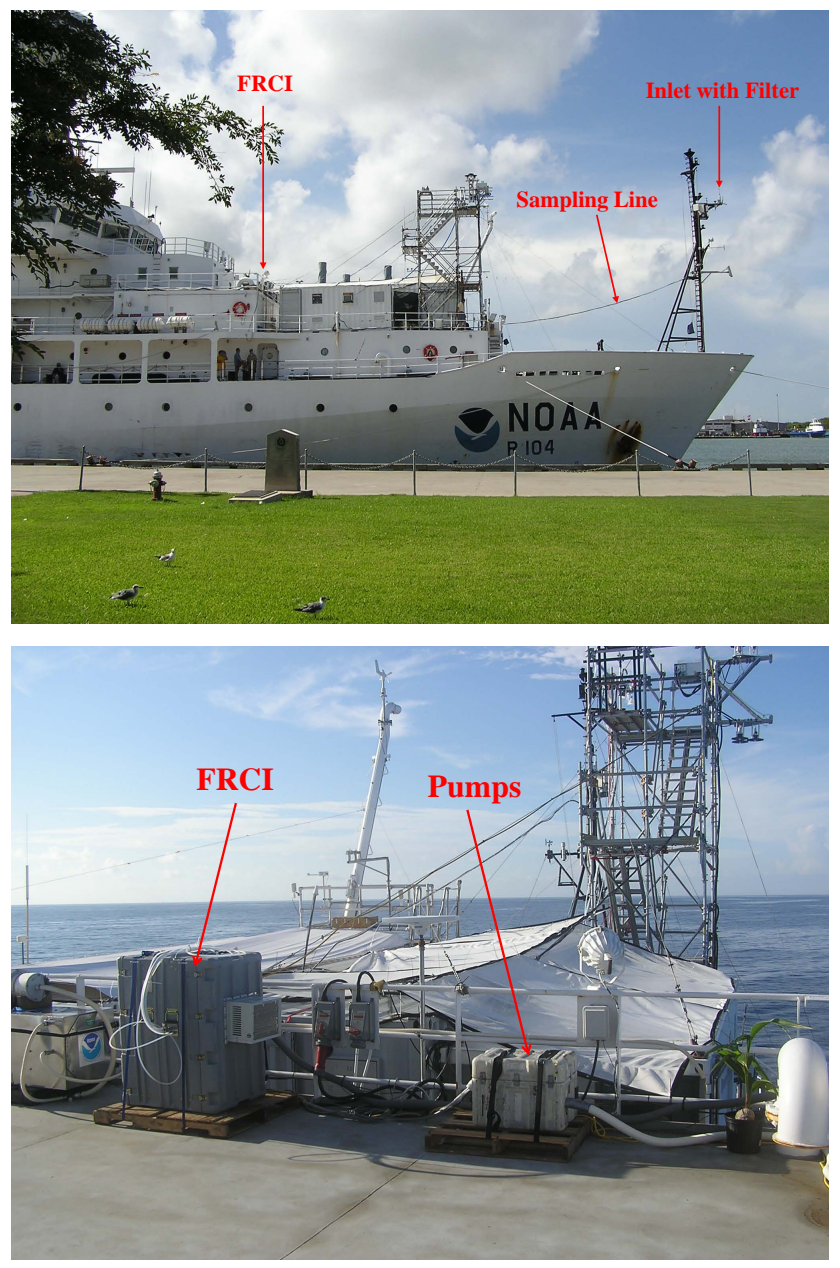

Fig. 2. Placement of the ozone measurement system during TexAQS and STRATUS. Upper picture: The inlet with a particle filter was located on the jackstaff near the sonic anemometer, with the sampling line running from the foremast to the ozone instrument on the deck. Bottom: The fast ozone instrument was deployed on the third deck. The large box on the pallet contained the fast response ozone chemiluminescence instrument, and the small box on the pallet to the right contained the pump system.

\section{Data processing and quality control}

Ozone concentrations were calculated by interpolation between bracketing calibration runs for most of the cruises, or by using the mean response factor obtained during the cruise (such as for GOMECC-2007). Continuous $10 \mathrm{~Hz}-$ ozone mixing ratio, wind, and motion data were processed in ten-minute blocks. Ozone fluxes were obtained by correlating the motion-corrected vertical velocity with the fast ozone fluctuations. A flowchart of the data processing procedure is given in Fig. 4; details pertaining to steps involved in this procedure are given in the following sections.

\subsection{Lag time}

The ozone signal is delayed in relation to the instantaneous sonic anemometer turbulence measurement due to the sample transport through the 30-m sampling line, and this lag time needs to be determined to correctly synchronize the ozone data to the turbulence data in the EC calculation. Initially, a cross-correlation analysis was used to compute the time lag between the two signals (Von Storch and Zwiers, 1999). Results from this determination are shown in Fig. 5. The crosses represent the calculated time lag between the ozone and vertical velocity time series for each ten-minute block between day of year (DOY) 209 and 214, and the dots are the hourly averages of these values. While these 10-min data show a relatively large scatter in the lag time results (due to poor cross-correlation results when small correlation exists between the ozone mixing ratio and the vertical wind component), the 1-hour averages and high number of data allow discerning a typical lag time of $\sim 4-6 \mathrm{~s}$ from these data. The data in Fig. 5 show a notable change in the lag time results over time. During DOY 209, the experimentally determined lag time was $\sim 6 \mathrm{~s}$. The lag time then gradually decreased over the next four days, eventually dropping to $\sim 4 \mathrm{~s}$ until the sampling line inlet filter was replaced at the beginning of DOY 212. After the filter change the lag time reverted back to its original value (6-7 s for this configuration). During TexAQS-2006, the sampling line inlet filter was located on the jackstaff to protect the full length of the sampling line from becoming contaminated, in particular from seasalt aerosol being drawn into the line and accumulating on the tubing walls. This filter was changed on a regular basis (after several days) during the cruise as the readings from the sampling line pressure sensor indicated its increasing flow resistance after a few days of use. The obvious explanation of the lag time drift and pressure observations is that the flow resistance through the filter gradually increased as particulate matter accumulated on the filter. This caused the line pressure to decrease as the MFC controlled the mass flow to remain constant. The decreasing pressure (at constant mass flow) caused a faster linear velocity and a gradual decrease of the lag time towards lower (faster) values.

Accurate shifting of the ozone data to match the turbulence data record is an important requirement for successful ozone flux determination. The drift in the lag time raised the question if and how much the ozone flux result is affected by the lag time drift and uncertainties in this behavior. This sensitivity was tested by artificially shifting the experimentally determined lag time by $0.5 \mathrm{~s}$ forward and backward. This analysis resulted in ozone flux values that differed to up to $\pm 6 \%$ of the original value. From this experiment, it became evident that either regular, good quality lag time determinations were required, or alternatively, more frequent filter changes, in order to prevent these drifts and associated errors in the ozone flux calculation. Inlet filter changes required climbing of the jackstaff, which frequently could not 

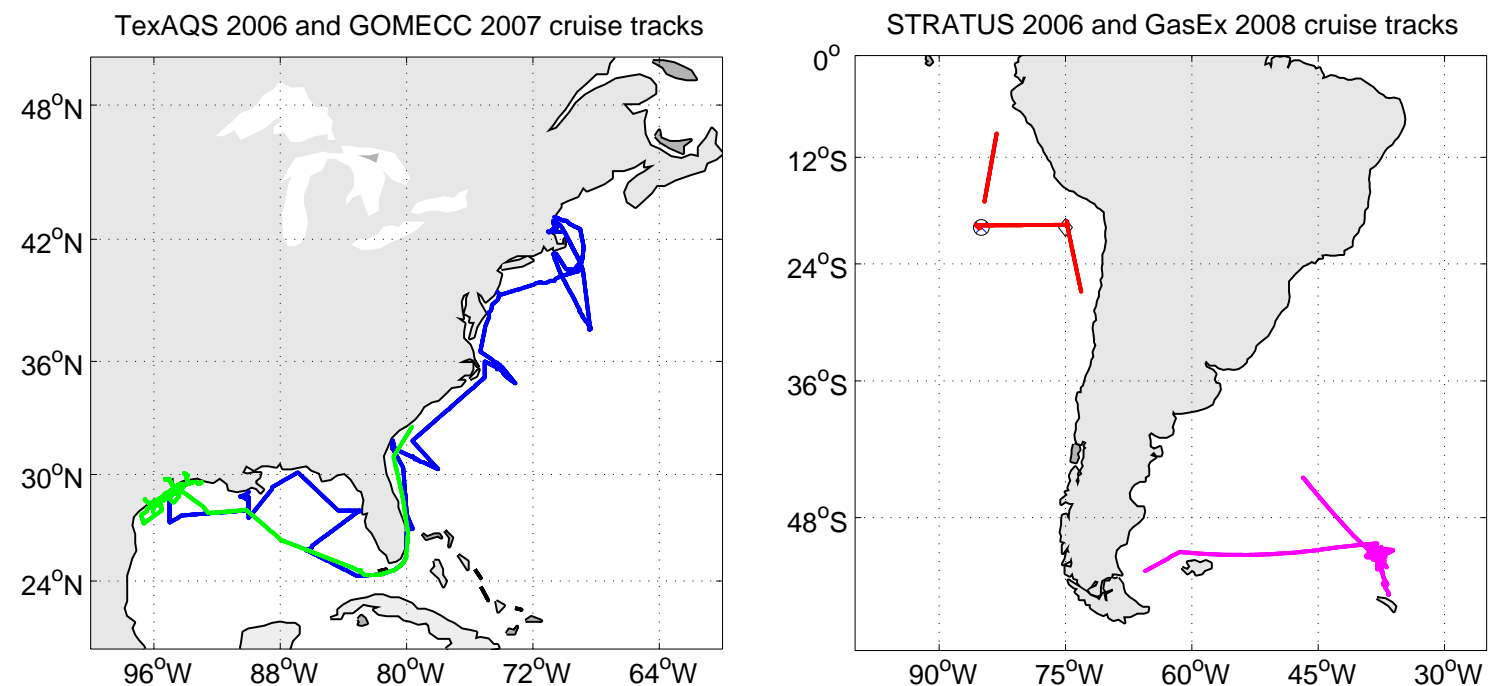

Fig. 3. Cruise tracks of the NOAA ship Ronald H. Brown during TexAQS-2006, STRATUS-2006, GOMECC-2007, and GasEx-2008. The TexAQS cruise (green) took place mainly off the coast of Texas and along the Houston and Galveston Ship channels between 27 July and 12 September 2006. The GOMECC cruise (blue) occurred between 10 July and 4 August 2007 along the US coast of the Gulf of Mexico and the US Atlantic coast. The STRATUS cruise (red) started in Panama on 9 October and ended in Chile on 27 October 2006. The GasEx cruise started in Punta Arenas, Chile, on 29 February and ended in Montevideo, Uruguay, on 11 April 2008 (magenta).

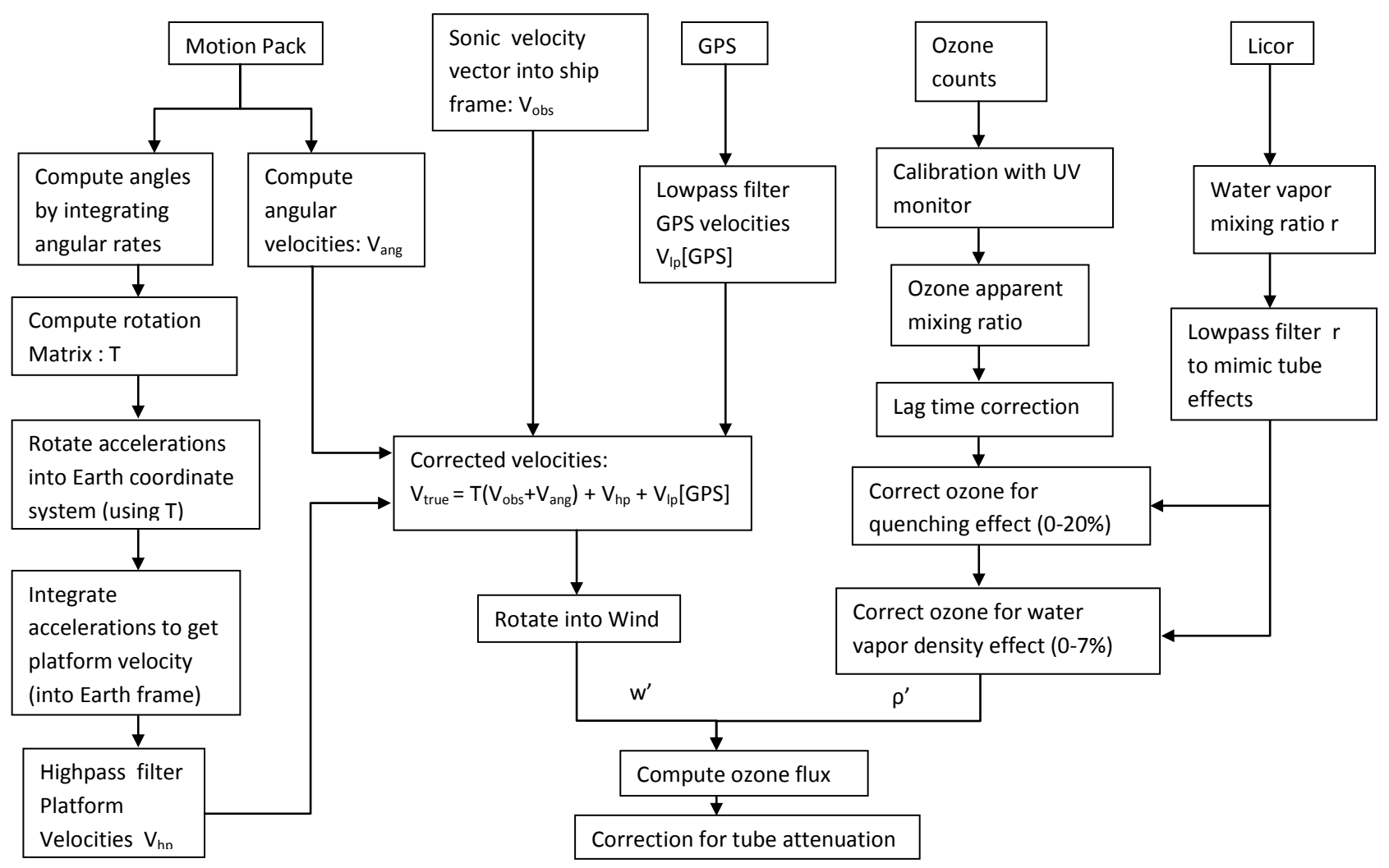

Fig. 4. Flowchart showing the steps in the ozone flux computation (including the water vapor interference correction). $T$ is the rotational coordinate transformation matrix as defined in Edson et al. (1998). 


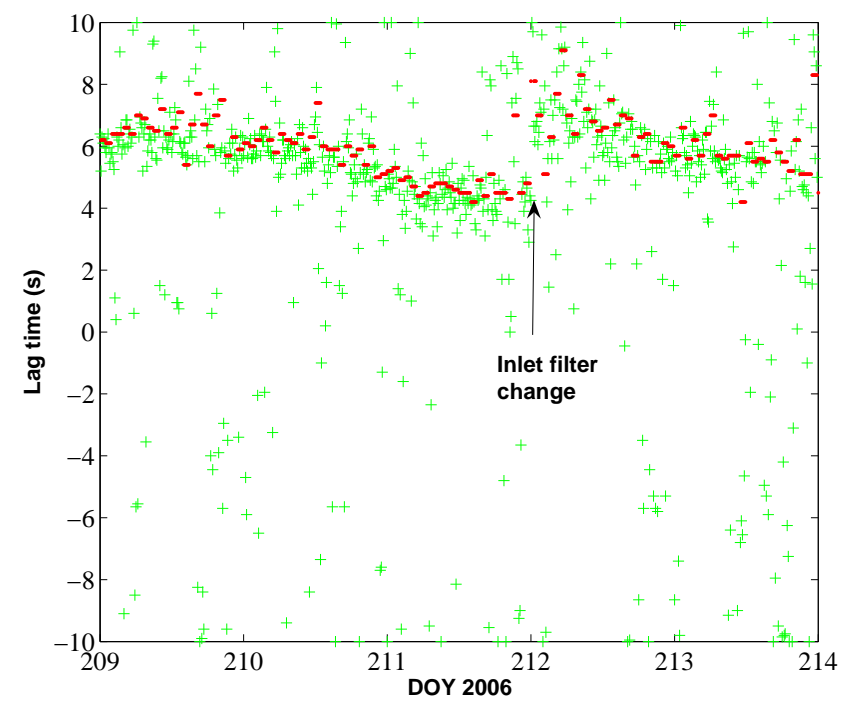

Fig. 5. Lag time results from the cross-correlation calculation for DOY 209-214 during TexAQS-2006. The crosses represent results for 10-min data analyses, and the dots show the hourly mean data of 10-min results that fell between 4 and $10 \mathrm{~s}$.

be done under rough sea, open ocean conditions (i.e. at high winds). Therefore, the filter was removed from the inlet on the jackstaff and instead an in-line filter holder was inserted into the sampling line nearer to the instrument box, where it could be easily accessed during all times while the ship was at sea, and thereafter the filter was changed daily during STRATUS-2006 and other subsequent cruises. During calibration runs on a later cruise we noticed a decrease in instrument sensitivity at lower sampling line purge rates. Closer investigation of this effect showed that the ozone transmission dropped significantly when sampling line purge rates were below $\sim 81 \mathrm{~min}^{-1}$. These losses were no longer observed after the line was replaced with a spare clean sampling tube. This ozone loss was also no longer observed after the first line had been cleaned again by purging with 1 . dilute hydrochloric acid, 2. hot tap water, 3. de-ionized water, and then re-conditioned with ozone-enriched air. Obviously, the line had become contaminated while it was used without the inlet filter on the mast, and this contamination resulted in ozone losses in the line at lower purge flow rates. The conclusion from these experiments is that an inlet filter is needed to protect the sampling line from accumulating contaminants, or regular recovery experiments or line cleanings need to be undertaken when no sampling line inlet filter is deployed.

The scatter in the lag time results (Fig. 5) from the crosscorrelation method and the difficulty in achieving results with this method during low ozone flux conditions made it desirable to find a more robust method for measuring and monitoring the time lag. This objective was accomplished by a "puff-system". This system facilitated daily injection of a small quantity of a reactant gas into the sample line, causing reaction (removal) of ozone during its transport to the

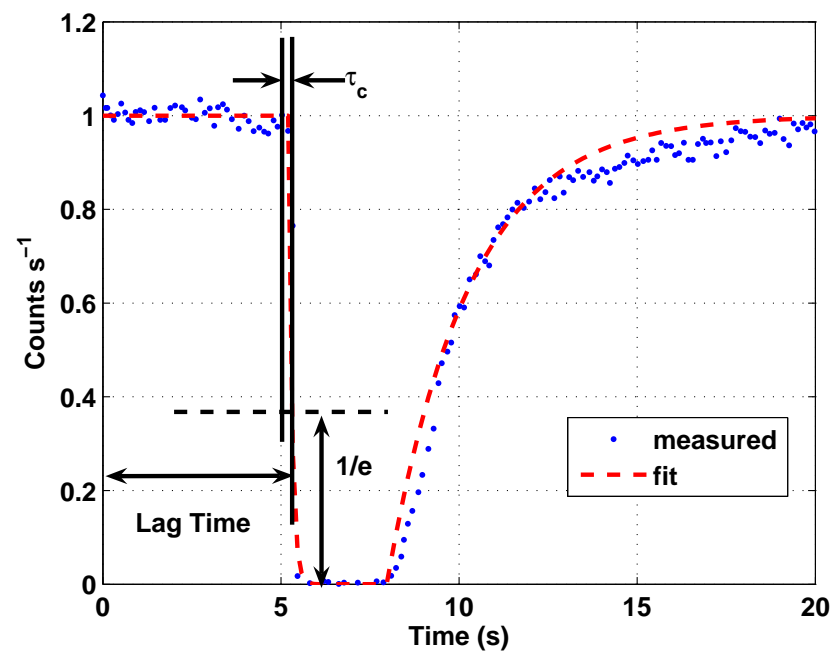

Fig. 6. Normalized step-response function obtained from a puff experiment. The dots represent the measured values, and the dashed curve is the result from a first-order low-pass response function.

FRCI, which was then detectable as a negative signal with the ozone sensor. For that purpose, a small pressurized gas cylinder containing $0.1 \%$ of nitric oxide in air was placed at the base of the jackstaff, and gas from the cylinder was delivered through a section of $0.32 \mathrm{~cm}$ o.d. stainless steel tubing to a small gas container ( $\sim 0.51$ volume) near the sampling inlet. A small volume of this gas mixture was injected into the main line by rapidly and briefly $(\sim 0.2 \mathrm{~s})$ opening an electrically actuated solenoid valve. The electrical pulse to the valve was also sent to the data system for recording the timing of the puff on the data acquisition system. Recorded data from one of these experiments are shown in Fig. 6. A few seconds after the puff, the FRCI ozone signal counts rapidly drop to near-zero. Then the signal recovers, but it takes a longer time to return to the starting value, which indicates that there is some residual nitric oxide retained in the sampling line manifold that takes a longer time to flush out of the system. Also added to this figure is the best fit of a first order low-pass step response curve function (Peters et al., 2001); the good agreement between the data and the computed curve shows that the measurements can be well approximated by this algorithm. Two important parameters can be retrieved from the negative step function in the signal response: 1 . the lag time and 2. the response time of the instrument (see more discussion below).

Results of regularly performed puff tests obtained during the GOMECC-2007 cruise are shown on Fig. 7. The upper panel of the figure displays the lag time measured daily during the cruise. The "puff tests" were performed within the first 10-min bin of the hour and were compared with the 10-min cross-correlation lag time results during that same hour. The dots are the puff test lag time results before the daily filter replacement, whereas the crosses are the values obtained after the filter change. Also plotted on this graph 

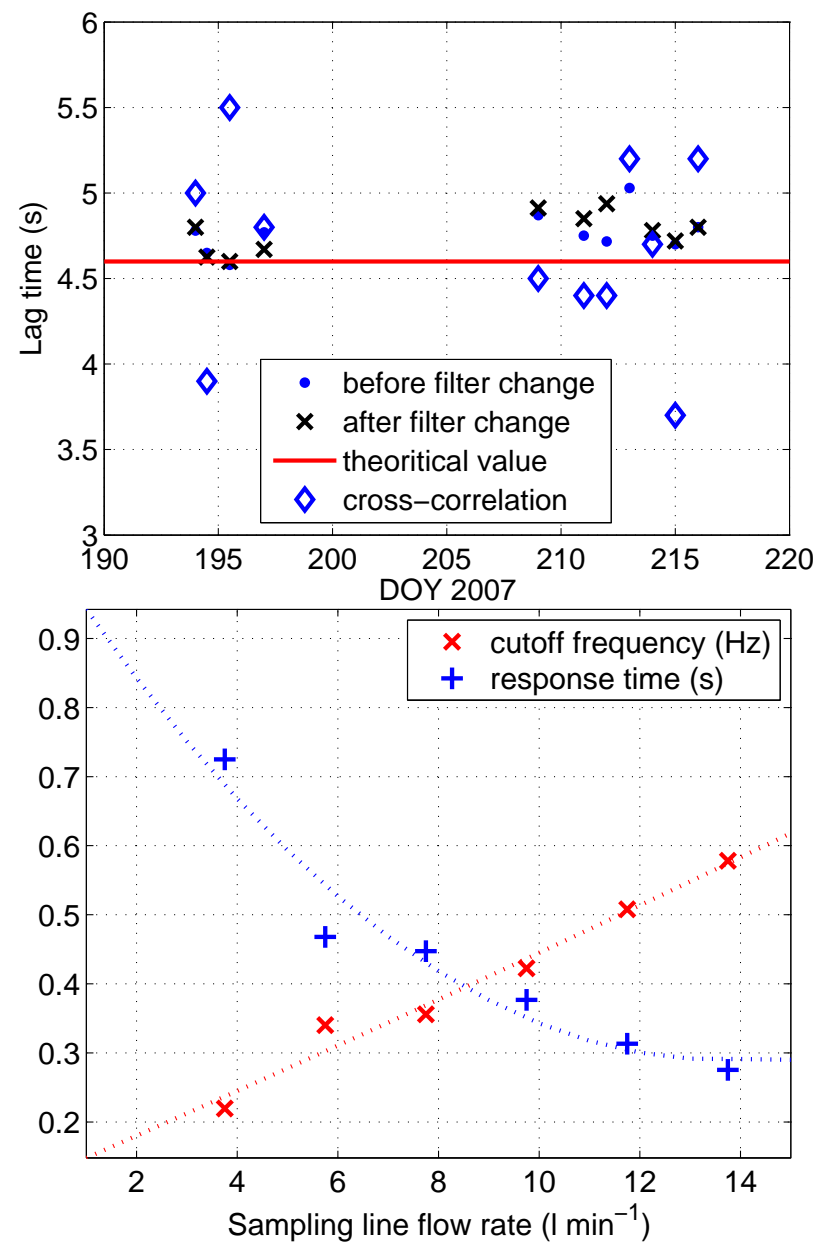

Fig. 7. Puff test results obtained during GOMECC-2007. The top panel shows the determined lag times from daily puff tests before and after filter changes, lag time results from the cross correlation method, and the theoretical lag time from consideration of the manifold volume and purge rate. The lower panel shows the response time of the instrument and cutoff frequency as a function of the total (line purge, reaction chamber, plus UV monitor) sampling line flow rate.

is the theoretical lag time estimate calculated at $4.6 \mathrm{~s}$ from the sampling line air flow rate, the tubing dimensions, and the pressure (estimated as the mean of ambient pressure and the recorded line pressure at the instrument). The puff data show that the lag time determined before, at $4.76 \pm 0.12 \mathrm{~s}$, and after the filter changes, at $4.77 \pm 0.12 \mathrm{~s}$, do not show any systematic difference, indicating that at these filter change intervals there was not enough time for particulate matter to accumulate on the filter to cause changes in the sample line purge time. Furthermore, there is no obvious trend in these data over the course of this cruise. The lag time results from the puff tests are more consistent, i.e. less variable, than results from the cross correlation determination (hourly mean values shown in Fig. 7). Nonetheless, despite the larger variability in the latter data, there is good agreement between the mean values from these different experiments, as well as with the theoretical value. The puff experiment has since been performed routinely on several other cruises, with results similar to those shown in this figure, i.e. standard deviations of $\sim 0.1 \mathrm{~s}$ for repeated determinations, and less than $\sim 0.2 \mathrm{~s}$ drift in the lag time results during 2-4 week-long cruises.

The time required for the signal to fall to $1 / \mathrm{e}$ of its initial value is defined as the response time of the measurement system. This time was determined from the $10 \mathrm{~Hz}$ data for puff experiments performed at varying total line purge rate. The lower panel of Fig. 7 presents results of this determination, as well as results for the cutoff frequency. The cutoff frequency is defined as the frequency where the fluctuations are attenuated by a factor of $1 / \sqrt{2}$ of the original value; the cutoff frequency can also be calculated as the inverse of the response time divided by $2 \pi$ (see Sect. 4.2). The residence time in the sampling line decreases with increasing flow rate, which also reduces mixing and other line effects that cause a "smearing" of the sample in the manifold. The response time approached $\sim 0.25 \mathrm{~s}$ at the highest flow rates that were achievable with our pump/mass flow controller/tubing configuration. With decreasing sample residence time in the manifold, the cutoff frequency increases accordingly, resulting in reduced loss of the measureable flux from high frequency attenuation. As the theoretical residence time in the reaction chamber was estimated at $0.04 \mathrm{~s}$ (see above), these results show that the response time is primarily determined by the sampling manifold and not by replacing the sample volume inside the reaction chamber. For the different system configurations used thus far, response times on the order of $\sim 0.25-0.40$ s have been achieved (cutoff frequencies of 0.4 to $0.6 \mathrm{~Hz}$ ). As shown below, this resolution allowed us to capture most ( $>90 \%$ ) of the ozone flux from the $18 \mathrm{~m}$-high inlet under typical ocean conditions.

\subsection{Signal attenuation effect}

Consider a pair of time series $x(t)$ and $w(t)$, where in our example $x$ represents the ozone concentration or the sonic temperature, and $w$ represents the vertical velocity. The variance spectral densities can be computed from, $S_{x x}(f)$ and $S_{w w}(f)$, and the cospectrum $C_{w x}(f)$, where $f$ is the frequency. The spectra are related to the variances $\sigma_{x}^{2}$ or $\sigma_{w}^{2}$ and the cospectrum to the covariance $\overline{w^{\prime} x^{\prime}}$.

$$
\begin{aligned}
\sigma_{x}^{2} & =\int_{0}^{f_{n}} S_{x x}(f) d f \\
F_{x} & =\overline{w^{\prime} x^{\prime}}=\int_{0}^{f_{n}} C_{w x}(f) d f
\end{aligned}
$$

Here the primes denote fluctuations about the mean, and $f_{n}$ is the Nyquist frequency for a digital time series. In EC, 
we are interested in the covariance of vertical velocity, $w$, with atmospheric constituents ( $x=$ temperature or ozone concentration). The ozone sensor produces a time series that is subject to a time delay and lowpass filtering caused by transmission of the air sample through the $30-\mathrm{m}$ sampling line to the reaction chamber. In this section, we discuss the reduction in covariance caused by filtering (smoothing) effects of the sampling manifold and the instrument reaction chamber. This is a fairly standard problem in micrometeorology, and several approaches are available to address it (see Massman and Clement, 2004, for a review).

Assuming that the combined sample tube and measurement chamber filter effect is reasonably represented by a simple first-order filter process, measured quantities are expected to be different from the intrinsic quantities associated with atmospheric variability:

$$
\begin{aligned}
\sigma_{x m}^{2} & =\int_{0}^{f_{n}} S_{x x m}(f) d f=\int_{0}^{f_{n}} S_{x x}(f) H(f) d f \\
F_{x m} & =\overline{w^{\prime} x^{\prime}}{ }_{m}=\int_{0}^{f_{n}} C_{w x}(f)[H(f)]^{1 / 2} d f=\int_{0}^{f_{n}} C_{w x m}(f) d f,
\end{aligned}
$$

where subscript $m$ denotes the measured signal, and $H(f)$ is the low-pass filter function characterized by the response time, $\tau_{c}$,

$$
H(f)=\left[1+\left(2 \pi f \tau_{c}\right)^{2}\right]^{-1}
$$

Note that the square root of the filter function occurs in the flux expression because only the $x$ (ozone) signal is attenuated. $H(f)$ will have a value of 0.5 at $f=f c$ (cutoff frequency). If the filter function chosen is a reasonable representation of the actual smoothing, then the true cospectrum can be estimated according to

$C_{w x}(f)=C_{w x m}(f) /[H(f)]^{1 / 2}$

Knowing the response time we can recover the true covariance from the measured cospectrum via

$F_{x}=\int_{0}^{f_{n}} C_{w x m}(f) /[H(f)]^{1 / 2} d f$

Flux data from the Table Mountain observations were used to estimate $\tau_{c}$ by comparing the w-ozone covariance, $C_{w \mathrm{O} 3}(f)$, with the covariance of vertical velocity and sonic temperature, $C_{w T}(f)$, under the assumption that the spectra and cospectra of scalars should be similar in the surface layer. This approach could not be used effectively with data from over the ocean because of the weak w-ozone covariance and noisy covariance spectrum. Ozone deposition over land is substantially larger than over the ocean, and the Table Mountain observations yielded sufficient ozone and temperature

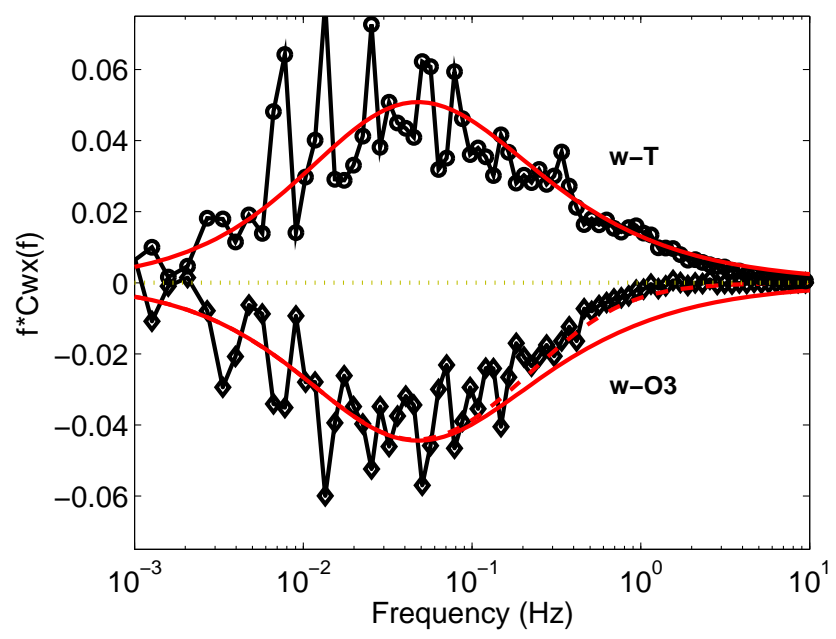

Fig. 8. Four-hour average cospectra from ozone flux measurements over land at the Table Mountain, CO, test site (DOY 152, 2006). Diamonds represent ozone in $\mathrm{ppb} \mathrm{ms}^{-1}$ and circles the sonic temperature in $\mathrm{Kms}^{-1}$. The solid lines are the Kaimal et al. (1972) cospectral model fits; the dashed line shows the result of the filtered/modeled result for ozone.

$w$-cospectra for this determination. We examined two fourhour periods during the afternoon of DOY 152 when adequate conditions for this analysis were observed. Winds were steady at $2-3 \mathrm{~ms}^{-1}$, the surface layer was convectively unstable, and reasonable velocity cospectra were measured for ozone and temperature.

The averaged cospectra shown in Fig. 8 were from the 4-h period beginning at 20:00 GMT and ending at 23:59 GMT. Also shown in this figure is a parameterization of cospectral shape from Kaimal et al. (1972):

$\frac{f C_{w x_{-} K}(f)}{F_{x}}=\frac{11 n}{(1+13.3 n)^{7 / 4}}$

where $n=f z / U$ is the surface-layer normalized frequency, $z$ is the inlet height above the surface, and $U$ is the mean wind speed. The model is clearly a reasonable fit to the $w-T$ cospectrum. The high-frequency smoothing effect of the sampling manifold and reaction chamber is apparent in the $w-\mathrm{O}_{3}$ cospectrum, as the relative loss of signal above $\sim 0.1 \mathrm{~Hz}$. The effect on the flux can be computed by applying the filter function to the Kaimal spectrum

$F_{x m_{-} K}=\int_{0}^{f_{n}} C_{w x_{-} K}(f)[H(f)]^{1 / 2} d f$

To determine the filter response time of the sample system, we take the ratio of the normalized ozone cospectrum to the normalized temperature cospectrum

Ratio $=\frac{C_{w \mathrm{O} 3 m}(f) / F_{\mathrm{O} 3}}{C_{w T}(f) / F_{T}}$, 


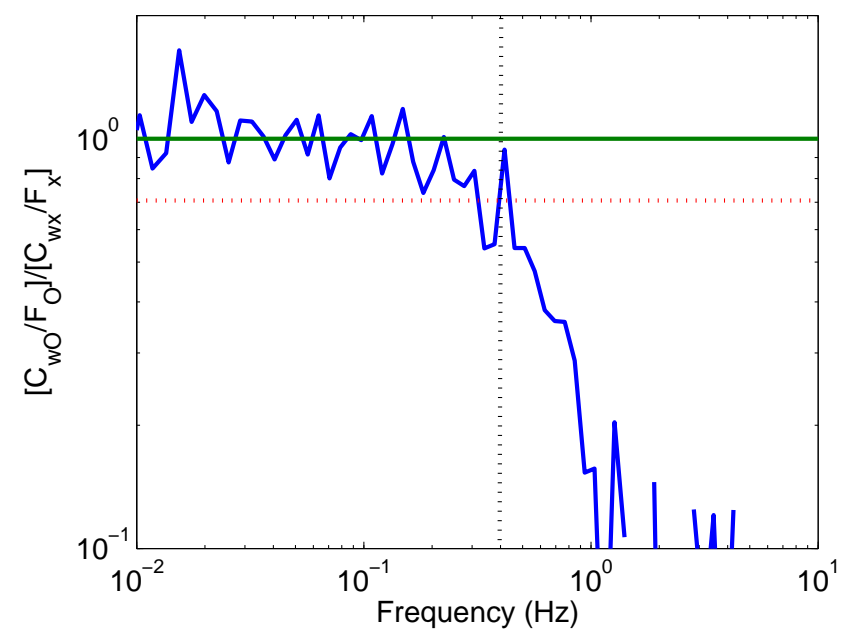

Fig. 9. Ratio of normalized cospectra from Fig. 8. The horizontal dotted line indicates a ratio of $1 / \sqrt{2}$, and the vertical dashed line shows a cutoff frequency of $0.4 \mathrm{~Hz}$.

where subscript $\mathrm{O}_{3}$ denotes the ozone, and $T$ the temperature. Here, we assume that the temperature and velocity signals are not lowpass filtered, and $F_{\mathrm{O} 3}$ is computed from the measured cospectrum from Eq. 7. This ratio is shown in Fig. 9 and indicates $\tau_{c}^{-1}=2 \pi f_{c} \approx 2 \pi \cdot 0.4$, or $\tau_{c} \approx 0.4 s$. This value, obtained via a fit function, is in good agreement with the $\sim 0.3 \mathrm{~s}$ time that was obtained from the puff experiment at the flow rates $\left(>101 \mathrm{~min}^{-1}\right)$ typically used in these measurements (Fig. 7).

The Kaimal model can be used to estimate the reduction in covariance, $F_{x m_{-} K} / F_{x_{-} K}$, associated with the sample manifold constant for the field observations from the Ron Brown. Here, height was set to $z=18 \mathrm{~m}$ to correspond to the inlet height on the ship, and Eq. 9 was used for selected values of relative wind speed. The results are shown in Fig. 10. Also included are calculations using the model from Horst (1997)

$$
\frac{F_{x m}}{F_{x}}=\left[1+\left(2 \pi n_{m} \tau_{c} U / z\right)^{\alpha}\right]^{-1}
$$

which gives the normalized cospectral peak as $n_{m}=0.085$ and $\alpha=7 / 8$ for unstable conditions. For a $4 \mathrm{~m} \mathrm{~s}^{-1}$ wind speed, the reduction in covariance caused by the sampling manifold is about 5-6\%.

\subsection{Water vapor effects}

The chemiluminescence signal has been shown to be sensitive to quenching by other molecules such as $\mathrm{N}_{2}, \mathrm{CO}, \mathrm{CO}_{2}$, and especially water vapor (Matthews et al., 1977). The relative loss of signal from the quenching by water vapor in the sample air and its effect on the apparent mixing ratio of ozone was studied in detail by Lenschow et al. (1981) and Ridley et al. (1992). Lenschow et al. (1981) expressed the corrected ozone mixing ratio $S_{\mathrm{O} 3}$ by

$S_{\mathrm{O} 3}=(1+\alpha r) S_{\mathrm{O} 3 m}$,

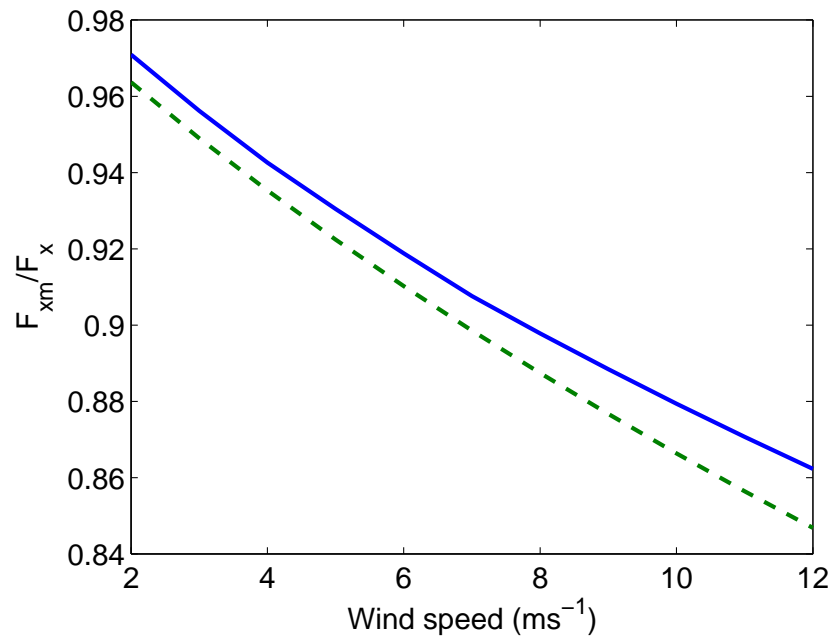

Fig. 10. Relative wind speed dependence of the ozone sample tube smoothing correction assuming $\tau_{c}=0.4 \mathrm{~s}$ for the experimental set up on the NOAA Ship Ronald H. Brown $(z=18 \mathrm{~m})$. The solid line represents the Kaimal model and the dashed line is the expression from Horst (1997).

where $S_{\mathrm{O} 3 m}$ is the measured ozone volume mixing ratio in ppbv, $\alpha$ is a proportionality constant, and $r$ is the water vapor mass mixing ratio (dimensionless). As the $\alpha$ coefficient has not been determined for our instrument we selected the same value as Lenschow et al. (1981), i.e. $5 \pm 1$, to develop an estimate of this effect on the ozone flux measurement. Further future tests on our instrument are planned to extract $\alpha$ from the ratio of the "wet-air" sensitivity to the "dry-air" sensitivity versus the volume mixing ratio of water in ambient air. For TexAQS-2006, the mean mixing ratio of water vapor was 0.016, which, after applying the correction from Eq. 12, leads to an increase of the ozone flux of $\sim 25 \%$ (or a decrease in the calculated deposition velocity). Obviously, this correction in the ozone flux is non-negligible in the marine environment where the water vapor content is high and can have large variations.

As the FRCI measures the apparent mixing ratio of ozone relative to moist air, density corrections on the flux must also be applied (Webb et al., 1980). For our system configuration it is reasonable to assume that the temperature fluctuations of the sample air are attenuated through thermal exchange with the sampling line, thus no correction for heat flux is necessary. However, the water vapor fluctuations in the tube are maintained and a dilution correction must be applied to account for the variations of the ozone density caused by water vapor fluxes. To apply this correction, we used the instantaneous water vapor measurement from the open path hygrometer, and then used an equation similar to Eq. 12 with a $\alpha$-value of 1.61 , which in this case corresponds to the ratio of the molecular weight of dry air to the molecular weight of water vapour, and applied this to the lag time-corrected ozone time series data. The values of $r$ used in the quenching and dilution corrections were low-pass filtered to mimic the 


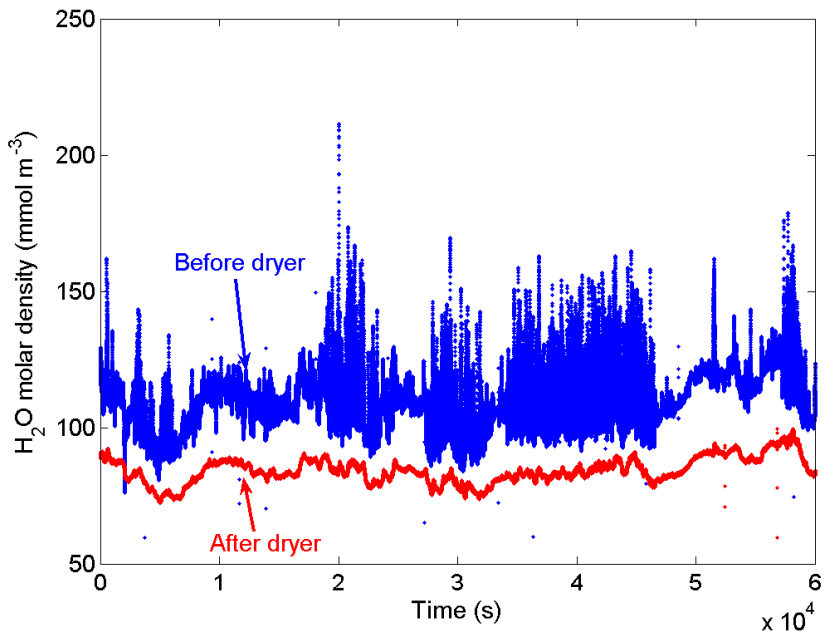

Fig. 11. Molar water vapor in ambient air during testing of the Nafion Dryer in Boulder. The noisier, upper time series data are from the LI-COR-7500 placed upstream of the Nafion system, and the lower signal is from the second, same type instrument downstream of the Nafion dryer.

effect of attenuation of the water vapor measurement at the end of the sampling line. For that purpose, a simple firstorder filter was used with a cutoff frequency of $0.4 \mathrm{~Hz}$. A potential lag time difference between water vapor and ozone (Ibrom et al., 2007) has not been evaluated explicitly in our system, as we did not have the ability to measure water vapor fluctuations in the sample cell. For comparison, the Webb correction was also applied using the EC method open path determined water vapor flux. This approach yielded practically the same result as point-to-point density corrections, providing confidence in the validity of our lag time correction. For TexAQS-2006, applying this correction led to an increase of the mean ozone flux by $8 \%$ (i.e. decrease in the ozone deposition velocity).

\subsection{Nafion membrane dryer}

In order to reduce the associated uncertainty in the water vapor effects and the applied corrections, a sample drying system was developed to reduce absolute levels and water vapor fluctuations and their influence on the ozone flux signal to levels that did not require applying corrections to the ozone signal. The Nafion drier (MD-110-48F, Perma Pure LLC, Toms River, NJ, USA) configuration, added to the system after the TexAQS and STRATUS experiments, is included in Fig. 1. This dryer was first tested in Boulder during ambient air sampling using two open path LI-COR-7500 sensors in a closed path configuration (by inserting a calibration tube into the measurement path). The two sensors were first intercompared without the dryer to determine the measurement offset of the two sensors, and all subsequent data were corrected for the determined instrument bias. Then, one instrument

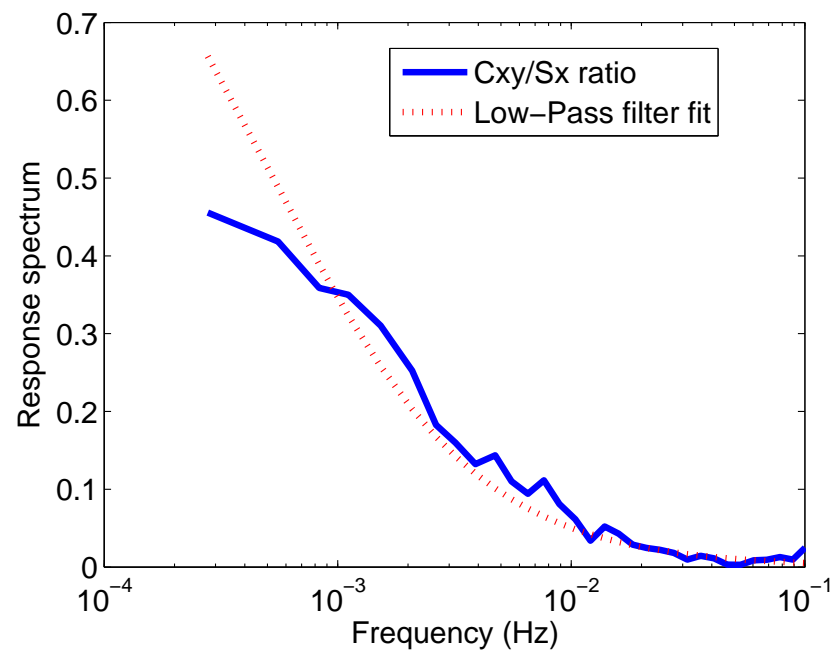

Fig. 12. Ratio of the cospectrum between the two LI-CORs before and after the Nafion $\left(C_{x y}\right)$ divided by the variance spectrum of the LI-COR before the Nafion $\left(S_{X}\right)$. The dash line is a first-order lowpass function fit (with a time constant of $300 \mathrm{~s}$ ).

was placed upstream of the Nafion membrane, the other was placed downstream of it.

The results of these tests can be seen in Fig. 11 . These time series data show that in this configuration the dryer removed $\sim 20-30 \%$ of the water vapor in the sample air, and that fast fluctuations of the water vapor signal were highly attenuated. The spectral distributions of the water vapor signal before and after the drier are shown in Fig. S5 (http://www.atmos-meas-tech.net/3/441/ 2010/amt-3-441-2010-supplement.pdf). The frequency response spectrum in Fig. 12 shows the correlation ratio $\left(C_{x y} / S_{x}\right)$, where $C_{x y}$ is the cospectrum between the two LICORs, and $S_{x}$ is the variance spectrum of the LI-COR before the dryer, which here is used to describe the response and performance of the Nafion system. The filter is reflected by the relative reduction in the signal as the frequency increases. By using the integral of the cospectrum in Eq. 11, we found that water vapor flux was reduced by about $98 \%$, which implies that the quenching effect on the ozone signal is fifty times smaller after the Nafion membrane. From these results, it appears that this dryer system is a good solution to eliminate fast water vapor fluctuations and required corrections that stem from the water vapor interferences on the ozone signal. There are no apparent reductions in the ozone fluctuations caused by the dryer (please note that we have not yet done systematic experiments to closer investigate the effect of the dryer on the fast ozone signal).

\subsection{Quality control and data filtering}

After applying all necessary corrections to the raw flux data, various additional criteria were considered to quality control the ozone flux data set. The usual criteria applied for 
filtering ship-based eddy covariance fluxes include relative wind direction (to eliminate unsuitable wind sectors), ship maneuvers (standard deviation of heading and ship's speed), and reasonable limits on certain other variables, such as ship motion correction. For computing the ozone fluxes, additional filters were required. The EC method relies on nearstationarity of $w^{\prime}$ and $x^{\prime}$; therefore data had to be examined for stationarity in ozone conditions, and periods with rapid changes in ambient ozone concentration were eliminated. Two criteria were used to determine and reject unstationary ozone conditions. First, the standard deviation of the $10 \mathrm{~Hz}$ data within the ten minute averaging period was used to determine the degree of fluctuation in ozone concentration over each 10-min measurement period. Secondly, a linear regression was applied to the 10-min data, and the slope of the regression line was used as an indicator for ozone concentration changes/trends over that period. The cut-off values for the various filters were adjusted between cruise conditions, and were in the range of 2-3 ppbv for the standard deviation, and 3-6 ppbv for the ozone mixing ratio change over time (10 min). All data that did not pass these quality indicators were rejected. Because these two methods efficiently eliminated low frequency artifacts in the time series, we did not apply the Ogive approach (Oncley et al., 1990) for further correction of stationary conditions

\section{Ozone deposition results}

In this section, we present some results from the TexAQS2006 and STRATUS-2006 experiment; the objective here is to provide a demonstration of the ozone flux measurement rather than an analysis of ozone deposition physics and chemistry. A more complete analysis and interpretation of all datasets from field campaigns since 2006 will be presented in subsequent publications (Lang et al., 2010; Grachev et al., 2010).

The TexAQS cruise offered a unique opportunity for making ozone flux observations while the ship was within both land and marine surface flux footprints, as seen in Fig. 13. To separate these regimes, a simple location filter was used with all data obtained more than $8 \mathrm{~km}$ offshore considered as offshore data. The data within the $8 \mathrm{~km}$ offshore limit were divided into two groups, one when the ship was in the proximity of the shore and bays, and the other one when the ship was in channels and canals and thus in proximity to the land. The geographical locations are represented in the map in Fig. 13. This figure also presents a statistical summary of the measured deposition velocities, where each histogram corresponds to one of the classification groups on the map. The left graph represents the offshore data only, where the determined mean deposition velocity was $v_{d}=0.034 \mathrm{~cm} \mathrm{~s}^{-1}$, with a standard deviation of $0.11 \mathrm{~cm} \mathrm{~s}^{-1}$ and a standard error of $\pm 0.003 \mathrm{~cm} \mathrm{~s}^{-1}$. This ozone deposition velocity result falls within the lower end of previous ozone flux data and
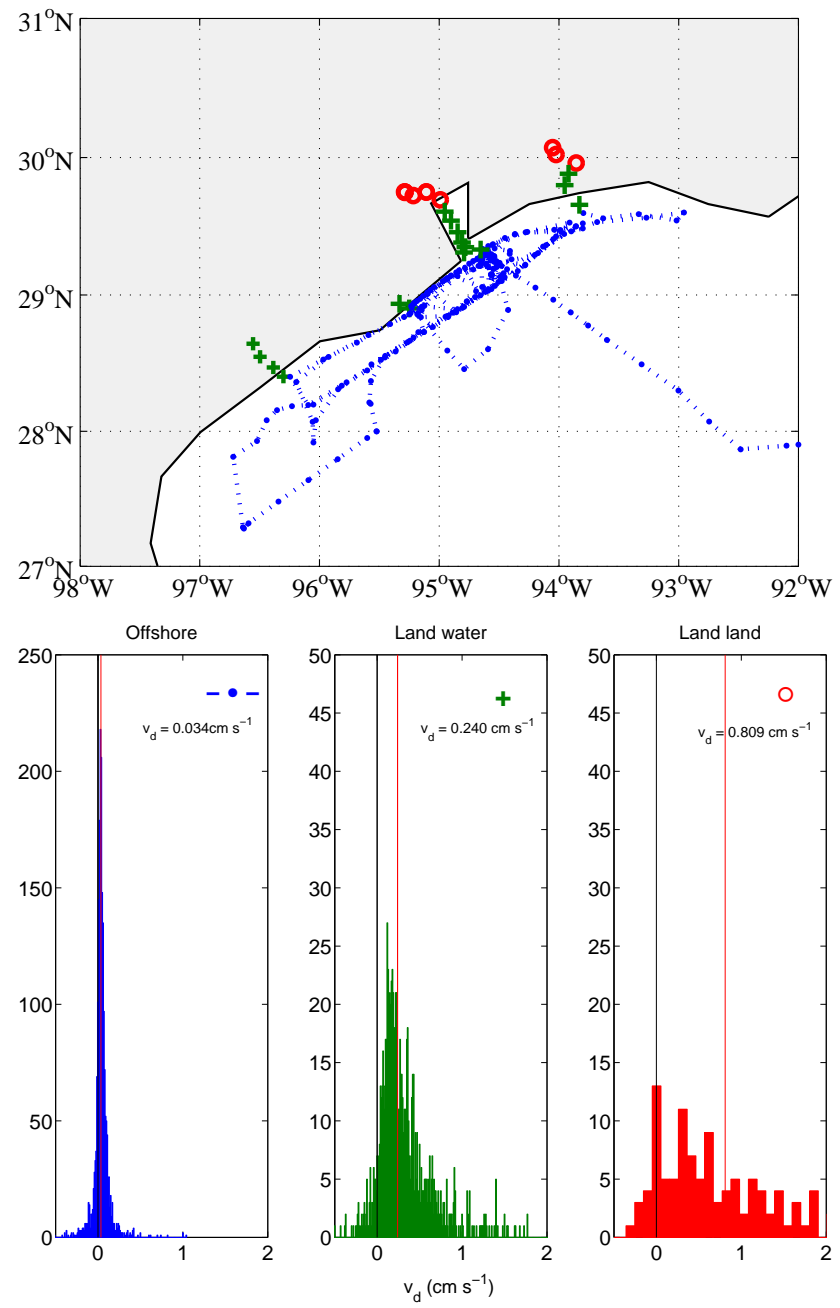

Fig. 13. The top panel shows the TexAQS-2006 cruise track broken up into three sampling categories. Dots represent the offshore locations, the plus signs represent the bay areas, and the circles show inland data. The lower panel depicts ozone deposition velocity result (for 10-min measurement segments) histograms corresponding to the three different sampling regions defined in the upper panel. The offshore data show a median ozone deposition velocity of $0.034 \mathrm{~cm} \mathrm{~s}^{-1}$ (indicated by vertical red line) for a total of 1953 number of points. The median ozone deposition velocity for the bay areas is $0.24 \mathrm{~cm} \mathrm{~s}^{-1}$ (937 number of points), and for the inland data the median is $0.81 \mathrm{~cm} \mathrm{~s}^{-1}$ (161 number of points).

assumptions presented in the literature. A significant fraction of the data (19\%, compared to $8 \%$ and $17 \%$ in the landwater and land-land histograms) is in the negative range, but nonetheless the high number of observations allows reducing the standard error to a margin where this ozone deposition result is well defined. The median ozone deposition velocity results $\left(v_{d} \pm\right.$ standard error) for the bay and channel areas were significantly higher, at $0.24 \pm 0.020 \mathrm{~cm} \mathrm{~s}^{-1}$ and $0.81 \pm 0.27 \mathrm{~cm} \mathrm{~s}^{-1}$, respectively. It is apparent that ozone 
deposition results are significantly more scattered and higher as the ship moved further inland. Note here that the standard error gets larger as the number of data points decreases and the scatter increases. Some care must be taken when looking at the mixed land/ocean data as confounding physical and chemical situations may occur. For instance, we also looked at the lake and bay areas and examined data from wind sectors that had sufficient over-water fetch. Selecting these situations only, the median ozone deposition value dropped from $0.24 \pm 0.020 \mathrm{~cm} \mathrm{~s}^{-1}$ to $0.065 \pm 0.019 \mathrm{~cm} \mathrm{~s}^{-1}$. This illustrates that a closer look at the inland data is necessary to explain the variability in this dataset. These comparisons show that the ship-borne ozone flux measurement captures the higher ozone uptake over coastal water and land footprints, where, due to higher deposition velocities to land and vegetation, ozone uptake is expected to be larger than over the ocean. This analysis adds credibility to the sensitivity of the ozone flux measurement as well as to the ozone flux results from the ocean observations.

As mentioned above, the standard deviation associated with the observed deposition velocity distribution for the offshore data set is larger than the mean value. To examine the possible sources for the sampling uncertainty in the deposition velocity, and thus explain the obtained standard deviation, we used an equation similar to Fairall et al. (2000):

$$
\frac{\sigma_{v_{d}}}{v_{d}}=\frac{\sigma_{w}}{\left(\frac{T}{\Gamma}\right)^{1 / 2} v_{d} \Delta X} \cdot\left(\left(\frac{3 \cdot v_{d} \cdot \Delta X}{u_{*}}\right)^{2}+\left(\gamma_{X}\right)^{2}+\frac{\phi_{\chi_{n}}}{4 \Gamma}\right)^{\frac{1}{2}},
$$

where $\sigma_{w}$ is the standard deviation of vertical velocity fluctuations (about $1.25 u_{*}$ ), $T$ is the averaging time period, $\Gamma$, as defined in Eq. 2 with $z \sim 18 \mathrm{~m}$ on the Ron Brown, $\gamma$ is a fraction of the atmospheric concentration $X$, and $\phi_{\chi_{\eta}}$ is the instrument white noise level in the ozone variance spectrum. $\Delta X$ is the surface-to-fluid difference of the concentration, which in our case is equal to $X$ as there is no ozone source from the ocean. From this equation the uncertainty in the ozone deposition velocity can be categorized as follows: 1) the first term inside the brackets represents the surface flux induced variance, i.e. the variance of ozone due to atmospheric processes correlated with $w^{\prime}$ near the surface; 2) the second term is the ozone variance associated with atmospheric processes uncorrelated with $w^{\prime}$ near the surface; 3) finally the third term is the random noise of the instrument. To look at the weight of these sources of uncertainty and to evaluate the relative standard deviation $\sigma_{v_{d}} / v_{d}$, we selected an hour when the ship was in the Gulf of Mexico and where recorded flux data passed all quality control criteria. On DOY 210, hour 11:00 GMT, the mean deposition velocity was $v_{d}=0.042 \mathrm{~cm} \mathrm{~s}^{-1}$ with a standard deviation $\sigma_{v_{d}}$ of $0.089 \mathrm{~cm} \mathrm{~s}^{-1}$ (computed from the six 10-min values in the hour), so the resulting measured relative standard deviation $\sigma_{v_{d}} / v_{d}$ was $\sim 2.1$. The mean ozone mixing ratio was $\sim 16 \mathrm{ppbv}$ resulting in a total of $\sim 55000$ counts s$^{-1}$ from the FRCI. The mean wind

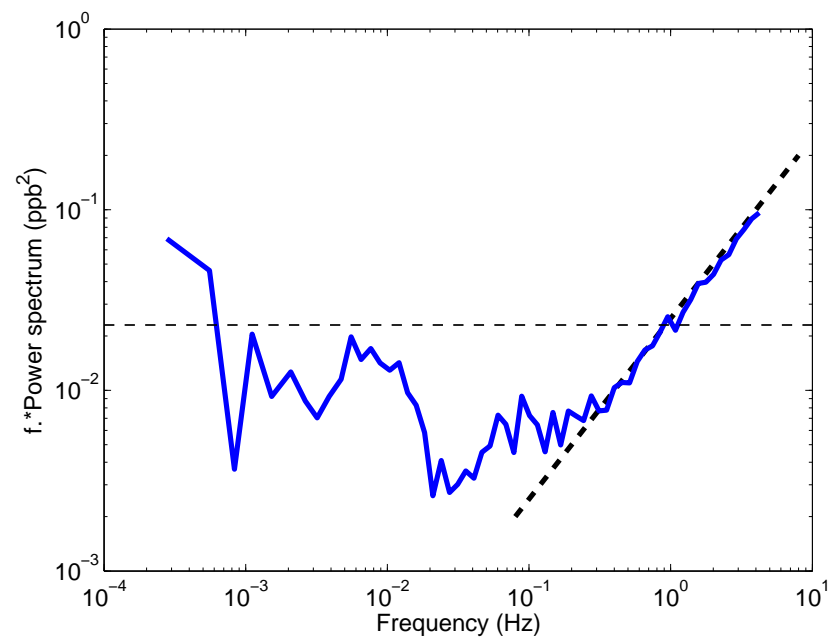

Fig. 14. One-hour average ozone spectrum from DOY 210, 11:00 GMT during TexAQS-2006. The horizontal dashed line indicates the white noise level at $2.3 \times 10^{-2} \mathrm{ppbv}^{2} \mathrm{~Hz}^{-1}$, and the bold dashed line shows a slope of +1

speed $U$ was $\sim 8 \mathrm{~m} \mathrm{~s}^{-1}$ with a mean friction velocity $u_{*}$ of $0.3 \mathrm{~m} \mathrm{~s}^{-1}$. The surface layer was near neutral conditions and $a$ (Eq. 2) was $\sim 3$. The variance spectrum for this hour is given in Fig. 14. The section indicated by a slope of +1 on the plot is the white noise level, $\phi_{\chi_{\eta}}$, and is about $2.3 \times 10^{-2} \mathrm{ppbv}^{2} \mathrm{~Hz}^{-1}$ or $3.7 \times 10^{-17} \mathrm{~mol}^{2} \mathrm{~m}^{-6} \mathrm{~Hz}^{-1}$. Multiplying this value by $5 \mathrm{~Hz}$ (the Nyquist frequency) gives a total variance for the white noise of $\sim 0.12 \mathrm{ppbv}^{2}$, or a standard deviation of $0.34 \mathrm{ppbv}$. For comparison, the counting noise, calculated as $\sqrt{N_{t}} /(\xi \Delta t)$, results in a standard deviation of $\sim 0.26 \mathrm{ppbv}(\Delta t=0.1 \mathrm{~s}) . N_{t}$ is the total number of counts measured in time $\Delta t$, and $\xi$ is the sensitivity of the instrument (counts $\mathrm{s}^{-1} \mathrm{ppbv}^{-1}$ of ozone). This confirms that instrument noise is determined principally by photon counting statistics and that the empirically determined $S / N$ was close to the theoretical value. Also, by comparing the surface flux induced variance (the first term inside the brackets in Eq. 13) with the internal sensor noise variance (the third term in Eq. 13), we found that for the selected hour the instrument noise was $\sim 1 / 4$ of the surface-driven sampling variability.

Using all previous values in Eq. 13, and neglecting the second term inside the brackets yields a $\sigma_{v_{d}} / v_{d}$ of $\sim 0.4$. Consequently, the first and third variance terms are too small to explain the relative standard deviation of 2.1 calculated from the observed data. To obtain that value, we had to select a $6 \%$ variability in the ozone concentration background $(\gamma=6 \%)$ in Eq. 13. This illustrates that for data that passed the stationarity criteria, the variability of the ozone background, $X$, not associated with surface turbulence can lead to a large uncertainty in the ozone deposition velocity measurement. Such variability can be observed during TexAQS-2006, where a significant fraction of data was influenced by high ozone 
variability when air in urban outflow with enhanced, photochemically produced ozone was sampled. The conclusion is that in the TexAQS case only a small fraction of the random variability in the deposition velocity estimates is caused by sensor noise. A similar study was performed with the STRATUS data set (graphs not shown), which covered remote ocean locations that are not influenced by ozone pollution. Here, under the more consistent ambient ozone mixing ratios, the mean deposition velocity was $v_{d}=0.009 \mathrm{~cm} \mathrm{~s}^{-1}$ with a standard deviation of $0.037 \mathrm{~cm} \mathrm{~s}^{-1}$ and a standard error of $\pm 0.001 \mathrm{~cm} \mathrm{~s}^{-1}$.

\section{Summary}

This research demonstrates the first direct covariance measurements of air-sea ozone flux from a ship platform. This task was accomplished by integrating a fast-response chemiluminescence sensor into the NOAA/ESRL ship-based flux system. Under the operational conditions described here, the instrument was found to have a sensitivity of $\sim 2800$ counts $\mathrm{s}^{-1} \mathrm{ppbv}^{-1}$, which yielded a high enough signal-to-noise ratio to measure ozone fluxes at the ambient levels and deposition rates observed over the ocean. A number of data filters and corrections were applied to reduce errors and uncertainties in the ozone flux determination. Attenuation in covariance caused by the sampling manifold and the reaction chamber was described, and a cutoff frequency of $\sim 0.4 \mathrm{~Hz}$ was determined for a $111 \mathrm{~min}^{-1}$ sampling line purge flow rate. The time lag between the ozone and turbulent vertical wind speed was first determined by the cross correlation method, and subsequently a "puff-system" was developed for a more accurate and reliable method for the lag time determination. Quenching and density variations caused by water vapor were found to contribute errors in the ozone flux determination. A Nafion membrane dryer was shown to reduce fast water fluctuations to levels where corrections were no longer required. Use of the dryer eliminates uncertainties from the water vapor interferences.

During the TexAQS-2006 cruise, the mean ozone deposition velocity ( \pm standard error) was $0.036 \pm 0.003 \mathrm{~cm} \mathrm{~s}^{-1}$ for the Gulf of Mexico data set, while higher values were found when the ship was near land, i.e. $0.24 \pm 0.020 \mathrm{~cm} \mathrm{~s}^{-1}$. This is a reflection of the higher ozone deposition rates for coastal areas and the mixed water-land footprints sampled in this region. For the Eastern Pacific cruise, STRATUS-2006, the mean ozone deposition value was $0.009 \pm 0.001 \mathrm{~cm} \mathrm{~s}^{-1}$. These results suggest a notable variability in the ozone deposition behavior over the ocean. Future analyses of data from these cruises as well as anticipated new ocean deployments of this ozone flux system will investigate the dependence of ozone deposition rates on biological, chemical and physical ocean conditions.
Acknowledgements. This work was supported by the National Science Foundation under grant BE-0410058, the NOAA Health of the Atmosphere program, and the NOAA Carbon Cycle Program, project \#GC07-186. The authors wish to thank the crew of the NOAA R/V Ronald H. Brown for their exceptional efforts during the various cruises. Thanks also to all other participants who aided in the operation of the reported experiments.

Edited by: R. Volkamer

\section{References}

Blomquist, B. W., Fairall, C. W., Huebert, B. J., Kieber, D. J., and Westby, G. R.: DMS sea-air transfer velocity: Direct measurements by eddy covariance and parameterization based on the NOAA/COARE gas transfer model, Geophys. Res. Lett., 33, L07601, 10.1029/2006GL025735, 2006.

Blomquist, B. W., Huebert, B. J., Fairall, C. W., and Faloona, I. C.: Determining the sea-air flux of dimethylsulfide by eddy correlation using mass spectrometry, Atmos. Meas. Tech., 3, 1-20, 2010 , http://www.atmos-meas-tech.net/3/1/2010/.

Businger, J. A. and Delany, A. C.: Chemical sensor resolution required for measuring surface fluxes by 3 common micrometeorological techniques, J. Atmos. Chem., 10, 399-410, 1990.

Delany, A. C.: Fast-response chemical sensors used for eddycorrelation flux measurements, Adv. Chem. Ser., 232, 91-100, 1993.

Edson, J. B., Hinton, A. A., Prada, K. E., Hare, J. E., and Fairall, C. W.: Direct covariance flux estimates from mobile platforms at sea, J. Atmos. Oceanic Technol., 15, 547-562, 1998.

Fairall, C. W., White, A. B., Edson, J. B., and Hare, J. E.: Integrated shipboard measurements of the marine boundary layer, J. Atmos. Oceanic Technol., 14, 338-359, 1997.

Fairall, C. W., Hare, J. E., Edson, J. B., and McGillis, W.: Parameterization and micrometeorological measurement of air-sea gas transfer, Bound.-Layer. Meteor., 96, 63-105, 2000.

Fairall, C. W., Bradley, E. F., Hare, J. E., Grachev, A. A., and Edson, J. B.: Bulk parameterization of air-sea fluxes: Updates and verification for the COARE algorithm, J. Climate, 16, 571-591, 2003.

Gallagher, M. W., Beswick, K. M., and Coe, H.: Ozone deposition to coastal waters, Quart. J. Roy. Meteor. Soc., 127, 539-558, 2001.

Ganzeveld, L. and Lelieveld, J.: Dry deposition parameterization in a chemistry general-circulation model and its influence on the distribution of reactive trace gases, J. Geophys. Res., 100, 20999-21012, 1995.

Ganzeveld, L., Helmig, D., Fairall, C. W., Hare, J., and Pozzer, A.: Atmosphere-ocean ozone exchange - A global modeling study of biogeochemical, atmospheric and water-side turbulence dependencies, Global Biogeochem. Cy., 23, GB4021, doi:10.1029/2008GB003301, 2009.

Grachev, A. A., Bariteau, L., Fairall, C. W., Hare J. E., Helmig, D., Hueber, J., and Lang, E. K.: Turbulent fluxes and transfer of trace gases from ship-based eddy correlation measurements during TexAQS 2006, J. Geophys. Res., in preparation, 2010. 
Horst, T. W.: A simple formula for attenuation of eddy fluxes measured with first-order-response scalar sensors, Bound.-Layer. Meteor., 82, 219-233, 1997.

Huebert, B. J., Blomquist, B. W., Hare, J. E., Fairall, C. W., Johnson, J. E., and Bates, T. S.: Measurement of the sea-air DMS flux and transfer velocity using eddy correlation, Geophys. Res. Lett., 31, L23113, doi:10.1029/2004GL021567, 2004.

Kaimal, J. C., Izumi, Y., Wyngaard, J. C., and Cote, R.: Spectral characteristics of surface-layer turbulence, Quart. J. Roy. Meteor. Soc., 98, 563-589, 1972.

Kawa, S. R. and Pearson, R.: Ozone budgets from the dynamics and chemistry of marine stratocumulus experiment, J. Geophys. Res., 94, 9809-9817, 1989.

Lang, E. K., Bariteau, L., Fairall, C. W., Hare, J. E., Helmig, D., and Hueber, J.: Atmosphere-ocean ozone fluxes during the TexAQS 2006, STRATUS 2006, GOMECC 2007, GasEX 2008, and AMMA 2008 cruises, J. Geophys. Res., in preparation, 2010.

Lenschow, D. H., Pearson, R., and Stankov, B. B.: Estimating the ozone budget in the boundary-layer by use of aircraft measurements of ozone eddy flux and mean concentration, J. Geophys. Res., 86, 7291-7297, 1981.

Lenschow, D. H., Pearson Jr., R., and Stankov, B. B.: Measurements of ozone vertical flux to ocean and forest, J. Geophys. Res., 87, 8833-8837, 1982.

Lenschow, D. H. and Kristensen, L.: Uncorrelated noise in turbulence measurements, J. Atmos. Oceanic Technol., 2, 68-81, 1985.

Massman, W. J. and Clement, R.: Uncertainty in eddy covariance flux estimates resulting from spectral attenuation, in: Handbook of Micrometeorology, A Guide for Surface Flux Measurement and Analysis, edited by: Lee, X., Massman, W. J., and Law, B. E., Kluwer, 67-99, 2004.

Matthews, R. D., Sawyer, R. F., and Schefer, R. W.: Interferences in chemiluminescent measurement of $\mathrm{NO}$ and $\mathrm{NO}_{2}$ emissions from combustion systems, Environ. Sci. Technol., 11, 10921096, 1977.

McGillis W. R., Edson, J. B., Hare, J. E., and Fairall, C. W.: Direct covariance air-sea $\mathrm{CO}_{2}$ fluxes, J. Geophys. Res., 106, 1672916745, 2001.
McGillis, W. R., Edson, J. B., Zappa, C. J., Warem, J. D., McKenna, S. P., Terray, T. A., Hare, J. E., Fairall, C. W., Drennan, W., Donelan, M., DeGrandpre, M. D., Wanninkhof, R., and Feely, R. A.: Air-sea $\mathrm{CO}_{2}$ exchange in the equatorial Pacific, J. Geophys. Res., 109, C08S02, doi:10.1029/2003JC002256, 2004.

Oncley, S. P., Businger, J. A., Friehe, C. A., LaRue, J. C., Itsweire, E. C., and Chang, S. S.: Surface layer profiles, and turbulence measurements over uniform terrain in near-neutral conditions, Ninth Symposium on Boundary Layers and Turbulence, Amer. Meteor. Soc., 237-240, 1990.

Peters, G., Fischer, B., and Munster, H.: Eddy covariance measurements with closed-path optical humidity sensors: A feasible concept?, J. Atmos. Oceanic Technol., 18, 503-514, 2001.

Ridley, B. A. and Grahek, F. E.: A small, low flow, high-sensitivity reaction vessel for NO chemiluminescence detectors, J. Atmos. Oceanic Technol., 7, 307-311, 1990.

Ridley, B. A., Grahek, F. E., and Walega, J. G.: A small, highsensitivity, medium-response ozone detector suitable for measurements from light aircraft, J. Atmos. Oceanic Technol., 9, 142-148, 1992.

Shon, Z. H. and Kim, N.: A modeling study of halogen chemistry's role in marine boundary layer ozone, Atmos. Environ., 36, 42894298, 2002.

Stedman, D. H., Stuhl, F., Daby, E. E., and Niki, H.: Analysis of ozone and nitric-oxide by a chemiluminescent method in laboratory and atmospheric studies of photochemical smog, J. Air Pollut. Control Assoc., 22, 260-263, 1972.

Von Storch, H. and Zwiers, F. W.: Statistical Analysis in Climate Research, Cambridge University Press, Cambridge, UK, 228230, 1999.

Webb, E. K., Pearman, G. I., and Leuning, R.: Correction of flux measurements for density effects due to heat and water-vapor transfer, Quart. J. Roy. Meteor. Soc., 106, 85-100, 1980.

Whitehead, J. D., McFiggans, G. B., Gallagher, M. W., and Flynn, M. J.: Direct linkage between tidally driven coastal ozone deposition fluxes, particle emission fluxes and subsequent CCN formation, Geophys. Res. Lett, 36, L04806, doi:10.1029/2008GL035969, 2009. 